\title{
Carrier Detection in X-linked Severe Combined Immunodeficiency Based on Patterns of $X$ Chromosome Inactivation
}

\author{
Jennifer M. Puck, Robert L. Nussbaum, and Mary Ellen Conley \\ Joseph Stokes, Jr. Research Institute of the Children's Hospital of Philadelphia, Philadelphia, Pennsylvania 19104; \\ Howard Hughes Medical Institute, Philadelphia, Pennsylvania 19104; and Departments of Pediatrics and Human Genetics, \\ University of Pennsylvania Medical School, Philadelphia, Pennsylvania 19104
}

\begin{abstract}
The X-linked form of severe combined immunodeficiency (XSCID) is underdiagnosed because no methods have been available for detecting carriers. Although boys with XSCID are deficient in $\mathrm{T}$ cells, female carriers are immunologically normal. Carriers' normal immune function would be expected if all their $T$ cells were derived from precursors whose $X$ chromosome bearing the XSCID mutation was inactivated early in embryogenesis. Using somatic cell hybridization to separate the active and inactive $\mathbf{X}$ chromosomes and restriction fragment length polymorphisms to distinguish them, we have determined the lymphocyte $X$ inactivation pattern in XSCID carriers and their female relatives. In the $T$ cells of three carriers, the $X$ chromosome bearing the XSCID mutation was consistently inactive. Nonrandom $X$ inactivation was also found in the $T$ cells of one at-risk female, while two others had normal, random $X$ inactivation. This method constitutes a generally applicable carrier test for XSCID.
\end{abstract}

\section{Introduction}

The term severe combined immunodeficiency describes a heterogeneous group of genetic disorders characterized by profound abnormalities of both cellular and humoral immunity $(1,2)$. In North America, approximately $15 \%$ of children with severe combined immunodeficiency have inherited autosomal recessive defects in the enzymes adenosine deaminase or purine nucleoside phosphorylase (3). Most children with severe combined immunodeficiency who do not have a known enzyme defect have profound hypogammaglobulinemia and markedly reduced numbers of $T$ cells, but normal or elevated numbers of $B$ cells in the peripheral circulation $(1,2)$. In this group of patients, the nature of the genetic defects and the pathogenesis of the immunodeficiency remain unknown; however, that affected males outnumber females by approximately four to one $(1,2)$ implies that as many as $60 \%$ of these cases may be due to a genetic defect located on the $\mathrm{X}$ chromosome. However, there are no clear clinical or laboratory features that distinguish the child with $\mathrm{X}$-linked

A preliminary report was presented at the First Conference on Clinical Immunology, Sixth International Congress of Immunology, Toronto, Canada, 1986.

Address reprint requests to Dr. Puck, Division of Infectious Diseases, Children's Hospital of Philadelphia, 1 Children's Center, Philadelphia, PA 19104.

Received for publication 14 October 1986.

J. Clin. Invest.

(c) The American Society for Clinical Investigation, Inc.

0021-9738/87/05/1395/06 $\$ 1.00$

Volume 79, May 1987, 1395-1400 severe combined immunodeficiency (XSCID) ${ }^{1}$ from children with other forms of the disease, and only a small number of affected boys have a family history demonstrating X-linked inheritance.

A carrier test for XSCID would greatly improve our ability to diagnose and classify this group of disorders. Female carriers of XSCID are normal by all immunologic criteria; we have used this observation to develop a method for carrier detection that depends on the normal process of $\mathrm{X}$ chromosome inactivation. The Lyon hypothesis (4) states that permanent inactivation of one of the two X chromosomes occurs at random in every somatic cell early in embryogenesis of the female. Once inactivated, an $\mathrm{X}$ chromosome remains inactive in all descendants of that cell. Consequently, the T lymphocyte precursors of XSCID carriers will consist of two approximately equal populations of cells: one in which the $\mathrm{X}$ chromosome with the normal XSCID gene is active, and one in which the $\mathrm{X}$ chromosome bearing the XSCID mutation is active. We propose that the latter population of $\mathrm{T}$ cell precursors fails to mature and reach the peripheral circulation, just as $\mathrm{T}$ cell precursors in a male who has the XSCID mutation on his one $\mathrm{X}$ chromosome fail to mature. As a result, all the normal peripheral $T$ cells of an XSCID carrier should be derived from precursor cells in which the $\mathrm{X}$ chromosome bearing the normal allele for the XSCID gene is the active X. A major implication of this model is that the pattern of $\mathrm{X}$ inactivation in the peripheral $\mathrm{T}$ cells will appear to be nonrandom in XSCID carriers and can serve as a sensitive marker for the carrier state.

To test whether nonrandom $\mathrm{X}$ inactivation of $\mathrm{T}$ cells can identify carriers of the XSCID mutation, we needed a generally applicable assay for the $\mathrm{X}$ inactivation pattern of peripheral lymphocytes. We have developed such a method by combining two techniques: first, the formation of human/rodent hybrids to separate and identify the active and inactive human X chromosomes, and second, Southern blot hybridization with X-linked restriction fragment length polymorphisms (RFLPs) (5) to distinguish the two $\mathrm{X}$ chromosomes. We have used this method to assess the $\mathrm{X}$ inactivation pattern in the $\mathrm{T}$ cells of obligate female carriers of XSCID and their female relatives, and have confirmed that nonrandom inactivation is an accurate marker for the XSCID carrier state.

\section{Methods}

Individuals studied. Females in two unrelated, previously reported (6, 7) families with typical XSCID were studied. Both probands had markedly reduced numbers of autologous $T$ cells, normal or elevated numbers of

1. Abbreviations used in this paper: HPRT, hypoxanthine phosphoribosyltransferase; lod, log of odds; RFLP, restriction fragment length polymorphism; XSCID, X-linked severe combined immunodeficiency. 
B cells, absent mitogen responses, and very low concentrations of serum immunoglobulins. In Family 1 (pedigree not shown), the mother of the proband was studied. This woman had, in addition to her affected son, four brothers (6) who had died of severe infections before age one. In Family 2 (7), whose pedigree is shown in Fig. 1, all the women in generations I and II were tested.

Lymphocytes for cell fusion and genomic DNA. T cells were purified from monocyte-depleted peripheral blood by rosetting with $\beta$-aminoethylisothiouronium bromide-treated sheep erythrocytes (E rosetting) as previously described (8). Surface phenotyping by immunofluorescence was performed with monoclonal antibodies against the $T$ cell marker T3 (prepared from the OKT3 secreting cell line CRL8001 from the American Type Culture Collection, Rockville, MD), the B cell marker B1 (Coutler Electronics Inc., Hialeah, FL), the monocyte marker LeuM3 (Becton Dickinson Immunodiagnostics, Div. of Becton Dickinson \& Co., Orangeburg, NY), and the natural killer cell marker B73.1 (9) as previously described (8). Whole blood or Epstein-Barr virus-transformed B cell lines $(10,11)$ were used for genomic DNA preparation.

Production of hybrid clones. Cell fusions were performed as previously described (12); for each individual studied, $\sim 2-5 \times 10^{7} \mathrm{~T}$ cells were fused to $10^{7}$ RJK88 cells, male Chinese hamster lung fibroblasts from which the gene for hypoxanthine phosphoribosyltransferase (HPRT) has been deleted (13). Fused cells were plated into 10100 -mm plates and, $2 \mathrm{~d}$ later, exposed to selective medium that included $10^{-4} \mathrm{M}$ hypoxanthine and $5 \times 10^{-5} \mathrm{M}$ azaserine. Individual hybrid colonies were isolated using cloning rings and expanded in selective medium to $10^{8}$ cells, from which DNA was prepared. Because human/rodent hybrids tend to lose human chromosomes, but must retain the active human $\mathrm{X}$ if grown in selective medium, $90 \%$ of hybrids contained only one X chromosome. Hybrid clones that contained both human $\mathrm{X}$ chromosomes underwent further selection in $1.5 \times 10^{-5} \mathrm{M}$ 6-thioguanine (14), which is toxic only to cells that express HPRT. Subclones that spontaneously lost their active $\mathbf{X}$ chromosome could be expanded for DNA preparation. 5-20 hybrids could be harvested per $10^{7}$ human cells fused.

Southern blotting. High molecular weight DNA was prepared following published procedures (15). $5 \mu \mathrm{g}$ of DNA were digested with Taq I (Bethesda Research Laboratories, Gaithersburg, MD) at $8 \mathrm{U} / \mathrm{ug}$ for 8$16 \mathrm{~h}$ at $65^{\circ} \mathrm{C}$. Agarose electrophoresis, transfer to nylon membranes (AMF Cuno, Div. of AMF Inc., Meriden, CT) and DNA hybridization were carried out as described by Reed (16). Hybridization probes used were 19-2 (15) to detect polymorphism DXS3, 36B-2 (17) to detect DXS10, 22-33 (15) to detect DXS11, and fragment VIII of the Factor IX gene (18). Each of these RFLP loci consists of two alternative alleles.

Scoring of active $X$ chromosomes and statistical analysis. Independent hybrids were analyzed by Southern blotting for RFLP loci at which the woman under study had already been shown to be heterozygous. The number of active $X$ chromosomes bearing each of the RFLP alleles was recorded. Family studies were conducted whenever possible to determine

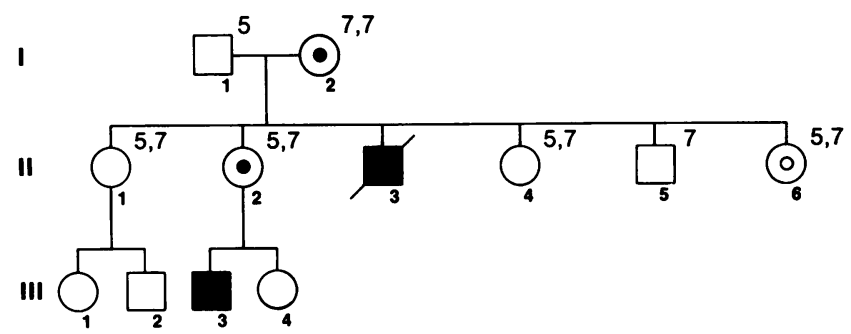

Figure 1. Pedigree demonstrating X-linked inheritance of severe combined immunodeficiency disease in Family 2 . Black and clear squares denote affected and normal males, respectively. Circles denote females. A black dot in a circle denotes a female obligate carrier, and a female predicted carrier, based on $\mathrm{X}$ chromosome inactivation pattern, is shown with an open dot in a circle. The superscript numbers refer to the sizes of DXS10 restriction digest fragments observed in Taq 1 digested Southern blots. which of the two alleles in the individual under study was on the same $\mathrm{X}$ chromosome as the XSCID mutation.

Statistical analysis was performed by the maximum likelihood ratio test (19). The null hypothesis of random $X$ inactivation was compared with an alternative hypothesis, that the cells used to form the hybrids consisted of a majority in which the active $\mathrm{X}$ chromosome carried a normal XSCID gene, mixed with a small fraction, $c$, of cells with randomly inactivated $\mathrm{X}$ chromosomes. When the RFLP allele on the $\mathrm{X}$ chromosome bearing the XSCID mutation could be identified, the odds were calculated as:

$\frac{(c / 2)^{r}(1-c / 2)^{N-r}}{(1 / 2)^{N}}$

where $N$ is the total number of active $\mathrm{X}$ chromosomes analyzed, and $r$ is the number of active $\mathrm{X}$ chromosomes carrying a mutant XSCID gene. When the XSCID mutation could not be proven to be on the same $X$ chromosome as one of the RFLP alleles, the odds were

$\frac{(1 / 2)(c / 2)^{r}(1-c / 2)^{N-r}+(1 / 2)(c / 2)^{N-r}(1-c / 2)^{N-r}}{(1 / 2)^{N}}$.

An odds ratio of 1,000:1 or greater (or $\log$ of odds [lod] $>3.0$ ) was considered statistically significant evidence on which to reject the null hypothesis (19). Analysis of $\sim 10-20$ hybrids will be required to yield a lod score of at least 3.0 if $c$ is $0-15 \%$.

\section{Results}

Somatic cell fusion experiments were performed using $\mathrm{T}$ lymphocytes from a normal control female, three obligate carriers of XSCID, and three at-risk family members. $T$ cells from a normal woman were fused to RJK88 cells, and hybrids were grown in selective medium. 11 hybrids were analyzed by Southern blotting: 4 demonstrated the RFLP allele from the maternally derived $\mathrm{X}$ chromosome, 5 showed the paternally derived allele, and 2 hybrids showed both. To make every hybrid informative for $\mathrm{X}$ chromosome inactivation, the hybrids that contained both RFLP alleles were washed free of the selective medium and grown in medium supplemented with 6-thioguanine, which is toxic to cells with an intact purine salvage pathway. This strategy permits the selective growth of cells that have lost the active $X$ chromosome. One of the two hybrids subcloned in 6-thioguanine retained only the maternal RFLP allele, and the other only the

Table I. X Chromosomal Alleles in Hybrids from Obligate Carriers of XSCID and a Normal Control

\begin{tabular}{|c|c|c|c|c|}
\hline \multirow[b]{2}{*}{ Human fusion partner } & \multicolumn{2}{|c|}{$\begin{array}{l}\text { Allele on active } \mathrm{X} \\
\text { chromosome }\end{array}$} & \multicolumn{2}{|c|}{ Significance } \\
\hline & 1 & $2^{*}$ & $\operatorname{lod}^{*}$ & $c^{4}$ \\
\hline & & & & $\%$ \\
\hline Normal control & 6 & 5 & 0 & \\
\hline Family 1 carrier & 2 & 22 & 3.93 & 16 \\
\hline Family 2 (I-2) & 20 & 1 & 4.27 & 10 \\
\hline \multirow[t]{2}{*}{ Family 2 (II-2) } & 17 & 0 & 5.12 & 0 \\
\hline & \multicolumn{4}{|c|}{ (Paternal) } \\
\hline
\end{tabular}

\footnotetext{
* The two alleles of different RFLPs were arbitrarily designated allele 1 and allele 2. RFLP loci used for the four individuals listed were DXYS1, DXS3, DXS3, and DSX10, respectively.

‡ Common logarithm of maximum likelihood ratio, where lod $>3.0$ is considered significant.

${ }^{\S}$ Maximum likelihood estimate of the percent of randomly inactivated cells in the population used for fusion.
} 
paternal allele. Thus, the active $\mathrm{X}$ in all 11 hybrids was identified and found to be maternal in five and paternal in six (Table I). These results indicated that in the $T$ cells of a normal female, the pattern of $X$ chromosome inactivation was random.

In contrast, the $X$ inactivation pattern in $T$ cells from three obligate carriers of XSCID was highly nonrandom. Using the RFLP DXS3, we found that 22 out of 24 hybrids made from T cells of the carrier in Family 1 had the same $X$ chromosome active. Again using DXS3, individual I-2 in Family 2 showed 20 out of 21 hybrids with the same $X$ chromosome active. Individual II-2 in Family 2 showed one $X$ chromosome that was used exclusively as the active $\mathrm{X}$ in all 17 hybrids analyzed. This degree of nonrandomness in the $\mathrm{X}$ inactivation pattern of lymphocytes of the obligate XSCID carriers was highly significant, as shown by the lod scores of 3.93 to 5.12 (Table I).

Southern blots for the RFLP DXS3 in representative hybrids from obligate XSCID carriers in Family 1 and Family 2 are shown in Fig. 2. One allele of the polymorphism DXS3 has a single band of 5 kilobases (kb) (5-kb allele) and the other allele has two bands of 2.8 and $2.2 \mathrm{~kb}(2.8 / 2.2-\mathrm{kb}$ allele), due to an extra Taq I site. In the far right lanes of Fig. $2, A$ and $B$, the presence of both alleles in genomic DNA from the two women indicated that they were heterozygotes for DXS3. In Fig. $2 A$, 13 of the 14 hybrids from the carrier in Family 1 contained an active human $\mathrm{X}$ chromosome with the 2.8/2.2-kb DXS3 allele, while the remaining hybrid, in lane 2 , had both $\mathrm{X}$ chromosomes. Analysis of hybrids from individual I-2 in the pedigree in Fig. 1 demonstrated a similar nonrandom $X$ chromosome inactivation pattern. As shown in Fig. $2 B$, only the 5-kb DXS3 allele was present in the majority of hybrids from this individual. This allele could be assigned to the active $X$ chromosome in 12 hybrids; both $\mathrm{X}$ chromosomes were present in three hybrids (lanes 2, 7, and 12); and, in the hybrid shown in lane 16, the 2.8/2.2$\mathrm{kb}$ allele was on the active $\mathrm{X}$ chromosome. Hybrids containing two $\mathrm{X}$ chromosomes were analyzed further by using 6-thioguanine to identify the active $X$ chromosome in each (data not shown).

It should be noted that the majority of active $\mathrm{X}$ chromosomes in the carrier from Family 1 had the $2.8 / 2.2-\mathrm{kb}$ allele, whereas the predominant active $X$ chromosome in individual I- 2 from Family 2 had the 5-kb allele. The RFLP alleles simply distinguish the two $\mathrm{X}$ chromosomes; no relationship exists between a particular allele and the XSCID mutation in different families.

Family studies in both the carrier in Family 1 and individual

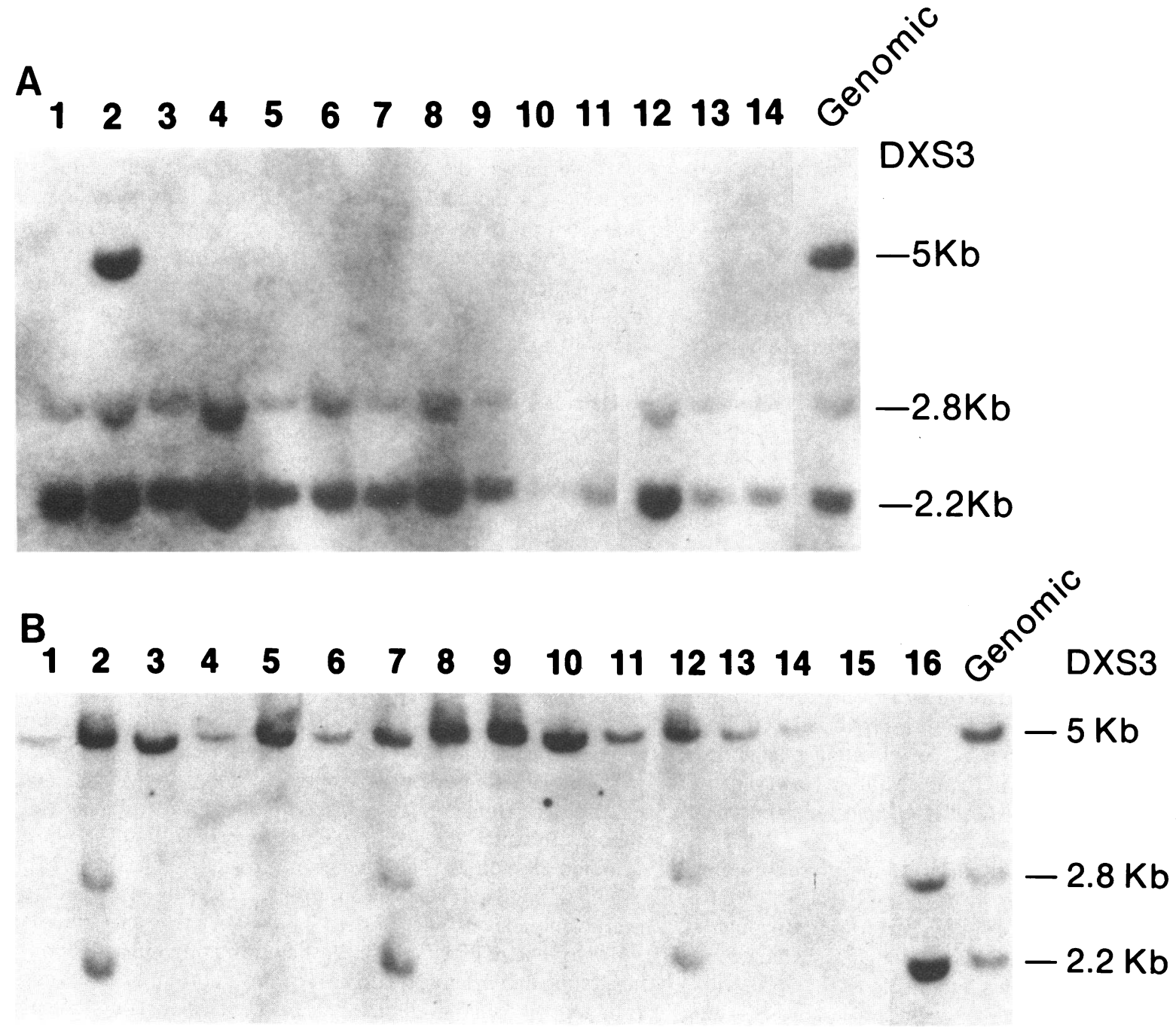

Figure 2. Southern blot analysis of Taq 1 digested genomic and hybrid DNA which were probed with 19-2 from $(A)$ obligate XSCID carrier in family 1 , and $(B)$ Individual I-2 in Family 2. 
I-2 from Family 2 did not allow a determination of which RFLP allele was located on the same X chromosome as the XSCID mutation. The data simply showed a highly significant nonrandom pattern of $\mathrm{X}$ inactivation. However, the results from a third obligate carrier, II-2 in Fig. 1, provided more information. This individual was heterozygous for another $\mathrm{X}$ chromosome RFLP, DXS10, which consists of either a 7- or a $5-\mathrm{kb}$ band in Taq 1 digests. As shown in the superscript numbers on the pedigree in Fig. 1, her mother was homozygous for the 7-kb allele, while her father was a 5-kb hemizygote. Thus, it was individual II-2's paternally derived X chromosome, with a normal XSCID gene, that had the 5-kb DXS10 allele, while her maternally derived $\mathrm{X}$ chromosome, with the mutant XSCID gene, must have had the 7-kb allele. All hybrids from the T cells of II-2 had the paternal $\mathrm{X}$ with the 5-kb allele as the active $\mathrm{X}$ chromosome, demonstrating that it is the X chromosome bearing the XSCID mutation that is consistently inactivated.

Although hybrid analysis demonstrated highly significant nonrandom $X$ inactivation in the $T$ cells of obligate carriers of XSCID, 3 of the 62 hybrids from obligate carriers in Table I were exceptions to the overwhelming majority. Two possible explanations for this finding are that $(a)$ the XSCID gene defect resulted in a relative rather than an absolute disadvantage in $\mathrm{T}$ cell maturation, or $(b)$ the $T$ cell population used to make the hybrids contained a small number of cells with random $\mathrm{X}$ chromosome inactivation. To explore these possibilities, cell surface markers on the $\mathrm{T}$ cells used to make the hybrids were analyzed by indirect immunofluorescence staining. $T$ cells separated by E rosetting were $97 \%$ rosette positive before lysis of the sheep erythrocytes; after lysis, $90 \%$ of the cells were positive for the T cell marker $\mathrm{T} 3,0.7 \%$ were positive for the B cell marker B1, 8.3\% were positive for the NK cell marker B73.1, and $1.5 \%$ were positive for the monocyte marker Leu-M3. If the $90 \%$ of cells that were $\mathrm{T} 3$ positive had totally nonrandom $\mathrm{X}$ inactivation, on average half of the remaining $10 \%$ that had random $X$ inactivation would have the XSCID gene on their active $X$ chromosome. The immunofluorescence analysis is consistent with the hypothesis that $5 \%$ of hybrids that carried the XSCID mutation on their active $X$ could be derived from the T3 negative cells, which constituted $10 \%$ of the cells used for fusion.

$\mathrm{X}$ chromosome inactivation patterns were also determined for three women in Family 2 (II-1, II-4, and II-6 in Fig. 1) who' were at risk for being carriers of XSCID. The DXS10 phenotype of the parents enabled us to predict that all of these women would be heterozygotes for this RFLP, with the $7 \mathrm{~kb}$ allele representing the maternally derived $\mathrm{X}$ chromosome. Analysis of the complete set of hybrids from the three sisters is shown in Table II. All 15 hybrids from individual II-6 had the paternal $\mathrm{X}$ active. This pattern of inactivation is more than 10,000 -fold more likely to be due to nonrandom inactivation than the alternative hypothesis of random $\mathrm{X}$ inactivation. However, the insignificant lod scores for II-1 and II-4 indicated random X inactivation for these women.

Fig. 3 illustrates the different $X$ inactivation patterns in carrier and noncarrier sisters in Family 2, using the RFLP DXS10. In Fig. $3 A$, a representative sample of hybrids from individual II4 showed random inactivation. The maternal $X$ chromosome functioned as the active $X$ in two hybrids (lanes 1 and 3), while the paternal $X$ chromosome was active in three (lanes 2,4 , and 5 ). In contrast, in Fig. $3 B$, all eight hybrids from II-6 used only the paternal $\mathrm{X}$ chromosome as the active $\mathrm{X}$.
Table II. X Chromosome Alleles in Hybrids from Females at Risk for Being a Carrier of XSCID

\begin{tabular}{|c|c|c|c|c|}
\hline \multirow[b]{3}{*}{ Human fusion partner } & \multicolumn{2}{|c|}{$\begin{array}{l}\text { DXS10 allele on active X } \\
\text { chromosome }\end{array}$} & \multirow{2}{*}{\multicolumn{2}{|c|}{ Significance }} \\
\hline & \multirow{2}{*}{$\begin{array}{l}\text { Maternal } \\
(7 \mathrm{~kb})\end{array}$} & \multirow{2}{*}{$\begin{array}{l}\text { Paternal } \\
(5 \mathrm{~kb})\end{array}$} & & \\
\hline & & & lod & $c$ \\
\hline & & & & $\%$ \\
\hline II-1 & 6 & 10 & 0.22 & 75 \\
\hline II-4 & 6 & 14 & 0.71 & 60 \\
\hline II-6 & 0 & 15 & 4.51 & 0 \\
\hline
\end{tabular}

Based on these results, individual II-6 was classified as an XSCID carrier, at risk for having affected sons, whereas individuals II-1 and II-4 were classified as noncarriers of the disease.

\section{Discussion}

We have shown that $\mathrm{T}$ cells from three obligate carriers of XSCID from two unrelated families exhibited nonrandom $X$ chromosome inactivation. For one of these carriers, parental studies proved that the inactive $\mathrm{X}$ chromosome was the one carrying the XSCID mutation. We also studied three women at $50 \%$ risk for carrying the gene for XSCID. In the T cells of one of these women, the X chromosome with the XSCID mutation was always inactive, while in cells from the other two, normal, random $\mathrm{X}$ inactivation was found.

Determining the $X$ inactivation pattern in $T$ cells required an assay for the active and the inactive $X$ chromosome and markers to distinguish the two $\mathrm{X}$ chromosomes. Somatic cell hybridization separates the two $\mathrm{X}$ chromosomes by using selection at the HPRT locus and, in doing so, identifies the active and inactive $X$. The two $X$ chromosomes are readily distinguished using RFLPS. Each $X$ chromosome is isolated in an individual clone and analyzed by Southern blotting for the RFLP allele it carries. With over 100 such X-linked RFLPs currently described (20), every woman is assured of being heterozygous at several loci; therefore, the $X$ inactivation pattern of the $T$ cells can be determined from a panel of hybrids made from $T$ cells. Any RFLP for which the woman being studied is heterozygous will serve to distinguish the two $\mathrm{X}$ chromosomes; because crossing over is extremely unlikely in somatic cells, the RFLP need not be linked to the XSCID locus.

The highly nonrandom $X$ inactivation in the $T$ cells of XSCID carriers indicates that each $T$ cell precursor requires a normal XSCID gene product in order to mature and proliferate. A mutation in the XSCID gene may be lethal to cells at a certain stage of differentiation or may result in a selective disadvantage in cell proliferation. Analysis of $\mathrm{X}$ inactivation patterns in various cell lineages from XSCID carriers may help identify the cell lineages in which the gene product is expressed and the point in differentiation at which the gene product first has its effect. We have made hybrids from a number of cell subsets, including purified monocytes, from carriers of XSCID. Preliminary results indicate that monocyte hybrids show random $X$ inactivation, suggesting that monocytes do not require a normal XSCID gene product for their development. This conclusion is consistent with the normal monocyte function seen in boys affected with XSCID. 


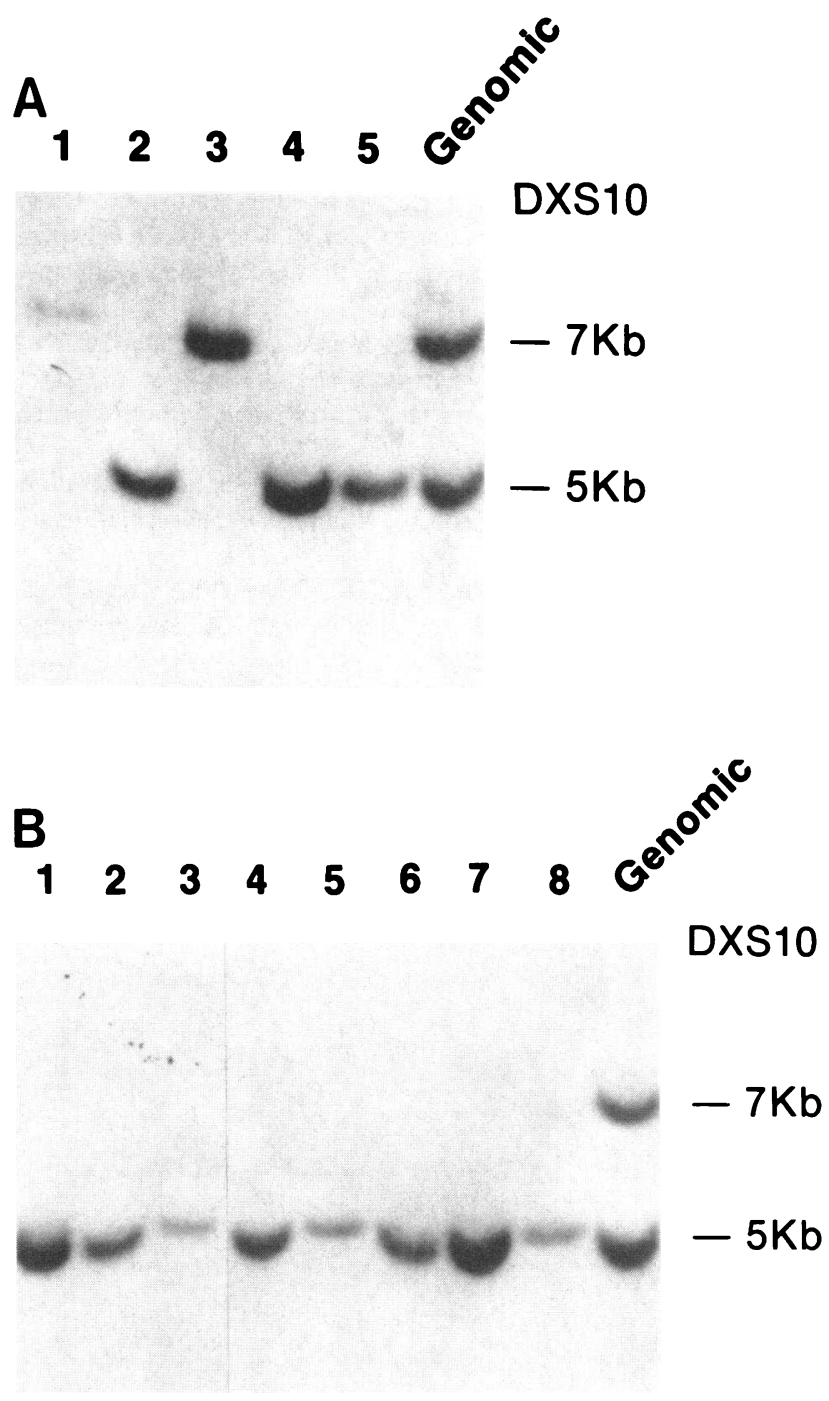

Figure 3. Southern blot analysis of Taq 1 digested genomic and hybrid DNA which were probed with 36B-2 from $(A)$ Individual II-4, Family 2 , and $(B)$ Individual II-6, Family 2.

Nonrandom $\mathrm{X}$ inactivation has been described previously in the tissues of female carriers of other X-linked hereditary disorders (21-23). In X-linked immunodeficiency in particular, nonrandom $\mathrm{X}$ inactivation limited to the $\mathrm{B}$ cells of obligate carriers of agammaglobulinemia has been reported by our laboratory (10) using heterozygosity for glucose-6-phosphate dehydrogenase as a means of distinguishing the two $\mathrm{X}$ chromosomes. The CBA/ $\mathrm{N}$ mouse was similarly shown to have skewed $\mathrm{B}$ cell $\mathrm{X}$ inactivation (24). Other investigators have reported similar observations in several cell types of carriers of Wiskott-Aldrich syndrome $(25,26)$. Analysis of $X$ inactivation patterns in cell subsets may be useful in a variety of $X$-linked diseases that affect lymphocyte maturation and proliferation, and may provide new insights into the normal differentiation of cell lineages of the immune system.

The ability to diagnose carriers of XSCID will contribute to genetic diagnosis and management in a number of important areas. First, genetic counseling will be more accurate for families with known XSCID. Second, a carrier test for XSCID will be particularly useful in the evaluation of recurrence risks for mothers of males with sporadic combined immunodeficiency of unknown type. Finally, a carrier test will provide many additional informative meioses for linkage analysis with RFLPs. For example, in the family in Fig. 1, there are only three informative meioses in the absence of a carrier test: II-2, II-5, and III-3. However, when the $\mathrm{X}$ inactivation pattern is known, four more individuals (II-1, II-4, II-6, and III-4) immediately become informative; the mother or siblings of I-2 may add even further information. Linkage analysis will be used to determine whether defects at a single locus or multiple loci can cause the disease and to map the locus or loci involved. The identification of RFLP markers closely linked to XSCID would be of immediate benefit for genetic counseling and prenatal diagnosis and may ultimately contribute to isolation and identification of the gene defect causing this disease.

\section{Acknowledgments}

We are indebted to Ms. Constance Briggs and Ms. Persymphonie Brown for their expert technical assistance. We thank Dr. Warren Ewens for his helpful discussion of statistical methods. We express our appreciation to the family members for their cooperation with our studies.

This study was supported by the Hassel Foundation, and by National Institutes of Health (NIH) grants AI-21477 and CA-15822. Dr. Puck was supported by NIH Physician Scientist grant HD-00657; Dr. Nussbaum is an Associate Investigator of the Howard Hughes Medical Institute.

\section{References}

1. Gelfand, E. W., and H. M. Dosch. 1983. Diagnosis and classification of severe combined immunodeficiency disease. Birth Defects Orig. Artic. Ser. 19:65-72.

2. Buckley, R. H., S. E. Schiff, H. A. Sampson, R. I. Schiff, M. L. Markert, A. P. Knutsen, M. S. Hershfield, A. T. Huang, G. H. Mickey, and F. E. Ward. 1986. Development of immunity in human severe primary $\mathrm{T}$ cell deficiency following haploidentical bone marrow stem cell transplantation. J. Immunol. 136:2398-2407.

3. Hirschhorn, R. 1983. Genetic deficiencies of adenosine deaminase and purine nucleoside phosphorylase: overview, genetic heterogeneity and therapy. Birth Defects Orig. Artic. Ser. 19:73-81.

4. Lyon, M. F. 1966. X-chromosome inactivation in mammals. $A d v$. Teratol. 1:25-54.

5. Botstein, B., R. L. White, M. Skolnick, and R. W. Davis. 1980. Construction of a genetic linkage map in man using restriction fragment length polymorphisms. Am. J. Hum. Genet. 32:314-331.

6. Fireman, P., H. A. Johnson, and D. Gitlin. 1966. Presence of plasma cells and gamma ${ }_{1}$ M-globulin synthesis in a patient with thymic alymphoplasia. Pediatrics. 37:485-492.

7. Conley, M. E., P. C. Nowell, G. Henle, and S. D. Douglas. 1984. $X X$ T cells and XY B cells in two patients with severe combined immune deficiency. Clin. Immunol. Immunopathol. 31:87-95.

8. Conley, M. E., and M. S. Bartlett. 1984. In vitro regulation of IgA subclass synthesis. II. The source of IgA2 plasma cells. J. Immunol. 133: 2312-2316.

9. Trinchieri, G., and B. Perussia. 1984. Human natural killer cells: biological and pathological aspects. Lab. Invest. 50:489-513.

10. Conley, M. E., P. Brown, A. R. Pickard, R. Buckley, D. S. Miller, W. H. Raskind, J. W. Singer, and P. J. Fialkow. 1986. Expression of the gene defect in X-linked agammaglobulinemia. N. Engl. J. Med. 315: 564-567.

11. Wilson, J. M., B. W. Baugher, P. M. Mattes, P. E. Daddona, and W. N. Kelley. 1982. Human hypoxanthine guanine phosphoribosyltransferase: demonstration of structural variants in lymphoblastoid cells 
derived from patients with a deficiency of the enzyme. J. Clin. Invest. 69:706-715.

12. Nussbaum, R. L., S. D. Airhart, and D. H. Ledbetter. 1983. Expression of the fragile $(\mathrm{X})$ chromosome in an interspecific somatic cell hybrid. Hum. Genet. 64:148-150.

13. Fuscoe, J. C., R. G Fenwick, D. H. Ledbetter, and C. T. Caskey. 1983. Deletion and amplification of the HPRT locus in Chinese hamster cells. J. Mol. Cell. Biol. 3:1086-1096.

14. Nussbaum, R. L., W. E. Crowder, W. L. Nyhan, and C. T. Caskey. 1983. A three-allele restriction-fragment-length polymorphism at the hypoxanthine phosphoribosyltransferase locus in man. Proc. Natl. Acad. Sci. USA. 80:4035-4039.

15. Aldridge, J., L. Kunkel, G. Bruns, U. Tantravahi, M. Lalande, T. Brewster, E. Moreau, M. Wilson, W. Bromley, T. Roderick, and S. A. Latt. 1984. A strategy to reveal high-frequency RFLPs along the human X chromosome. Am. J. Hum. Genet. 36:546-564.

16. Reed, K. C., and D. A. Mann. 1985. Rapid transfer of DNA from agarose gels to nylon membranes. Nucleic Acids Res. 13:72077221.

17. Boggs, B., and R. L. Nussbaum. 1984. Two anonymous X-specific human sequences detecting restriction fragment length polymorphisms in region Xq26-qter. Somatic Cell Mol. Genet. 10:607-613.

18. Winship, P. R., D. S. Anson, C. R. Rizza, and G. G. Brownlee. 1984. Carrier detection in haemophilia B using two further intragenic restriction fragment length polymorphisms. Nucleic Acids Res. 12:88618872.
19. Morton, N. E. 1955. Sequential tests for the detection of linkage. Am. J. Hum. Genet. 7:277-318.

20. Goodfellow, P. N., K. E. Davies, and H.-H. Ropers. 1985. Report of the committee on the genetic constitution of the $\mathrm{X}$ and $\mathrm{Y}$ chromosomes. Cytogenet. Cell Genet. 40:296-352.

21. Nyhan, W. L., B. Bakay, J. D. Connor, J. F. Marks, and D. K. Keele. 1970. Hemizygous expression of glucose-6-phosphate dehydrogenase in erythrocytes of heterozygotes for the Lesch-Nyhan syndrome. Proc. Natl. Acad. Sci. USA. 65:214-218.

22. Migeon, B. R., H. W. Moser, A. B. Moser, J. Axelman, D. Sillence, and R. A. Norum. 1981. Adrenoleukodystrophy: evidence for X linkage, inactivation, and selection favoring the mutant allele in heterozygous cells. Proc. Natl. Acad. Sci. USA. 78:5066-5070.

23. Wieacker, P., J. Zimmer, and H. Ropers. 1985. X inactivation patterns in two syndromes with probable X-linked dominant, male lethal inheritance. Clin. Genet. 28:238-242.

24. Nahm, M. H., J. W. Paslay, and J. M. Davie. 1983. Unbalanced $\mathrm{X}$ chromosome mosaicism in B cells of mice with X-linked immunodeficiency. J. Exp. Med. 158:920-931.

25. Gealy, W. J., J. Dwyer, and J. B. Harley. 1980. Allelic exclusion of glucose-6-phosphate dehydrogenase in platelets and T lymphocytes from a Wiskott-Aldrich syndrome carrier. Lancet. i:63-65.

26. Prchal, J. T., A. J. Carroll, J. F. Prchal, W. M. Crist, H. W. Skalka, W. J. Gealy, J. Harley, and A. Malluh. 1980. Wiskott-Aldrich syndrome: cellular impairments and their implication for carrier detection. Blood. 56:1048-1054. 